\title{
Morfologia e viabilidade de grãos de pólen de Toona ciliata M. Roemer (Meliaceae) em diferentes estádios florais e tempos de armazenamento
}

\author{
Morphology and viability of pollen grains of Toona ciliata M. Roemer \\ (Meliaceae) at different flower stages and storage times

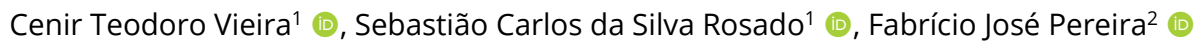 \\ ${ }^{1}$ Universidade Federal de Lavras - UFLA, Lavras, MG, Brasil \\ Universidade Federal de Alfenas - UNIFAL, Alfenas, MG, Brasil
}

Como citar: Vieira, C. T., Rosado, S. C. S., \& Pereira, F. J. (2020). Morfologia e viabilidade de grãos de pólen de Toona ciliata M. Roemer (Meliaceae) em diferentes estádios florais e tempos de armazenamento. Scientia Forestalis, 48(128), e3399. https://doi.org/10.18671/scifor.v48n128.02

\begin{abstract}
Resumo
Toona ciliata é uma espécie promissora devido às suas excelentes propriedades tecnológicas para uso na indústria madeireira. Adicionalmente, ressalta-se a sua boa adaptação às diversas condições edafoclimáticas brasileiras, resistência aos ataques da broca dos cedros e mognos (Hypsiphyla grandella), bem como as suas respostas satisfatórias às práticas silviculturais e de manejo. Entretanto, esta é uma espécie que ainda não foi geneticamente melhorada para o seu emprego em projetos de reflorestamento em larga escala. O presente trabalho teve o objetivo de gerar conhecimentos sobre a morfologia e viabilidade de grãos de pólen armazenados para solucionar os problemas decorrentes da assincronia na fenologia do florescimento de genitores preferenciais para, assim, dar início aos programas de polinização controlada. Após o reconhecimento inicial de importantes fatores relativos à biologia floral e sistema de cruzamento, coletaram-se, em um plantio em Campo Belo-MG, anteras de flores em três estádios de desenvolvimento: botão floral, em pré-antese e em antese. As anteras foram dessecadas e armazenadas a -16 C por um período de tempo de até 360 dias. Nesse período os grãos de pólen foram extraídos e analisados quanto a sua morfologia e viabilidade. O número de grãos de pólen por antera foi maior em botão floral e flor em pré-antese. O diâmetro dos grãos de pólen aumentou de forma gradativa de botão floral para flor em antese. Em botão floral a espessura da exina foi menor quando comparada aos outros dois estádios. A porcentagem de viabilidade dos grãos de pólen foi alta (acima de 88\%) nos três estádios de desenvolvimento da flor, mesmo após 360 dias de armazenamento. Isso permitiu concluir que o armazenamento de grãos de pólen pode exceder o tempo de 360 dias e que as polinizações controladas em programas de melhoramento genético de $T$. ciliata podem ser conduzidas com grãos de pólen provenientes de anteras de botões florais.
\end{abstract}

Palavras chave: Cedro australiano; Diâmetro do pólen; Sistema de cruzamento; Polinização controlada.

\begin{abstract}
Toona ciliata is a promising tree species due to its excellent technological properties for use in the timber industry. In addition, this specie has adapted well to the various Brazilian soil and climate conditions, shows resistance to the cedar and mahogany borer (Hypsiphyla grandella), and satisfactory responses to silvicultural and management practices. However, T. ciliata genetic improvement programs have not yet reached a satisfactory level for its use in large-scale reforestation projects. This work aimed to deepen our knowledge about morphology and viability of stored T. ciliata pollen grains in order to solve problems
\end{abstract}

Fonte de financiamento: Patrocínio privado da empresa Bela Vista Florestal.

Conflito de interesse: Nada a declarar.

Autor correspondente: cenir_vie@hotmail.com

Recebido: 31 maio 2019.

Aceito: 8 outubro 2019.

Editor: Paulo Henrique Müller Silva.

(i) Este é um artigo publicado em acesso aberto (Open Access) sob a licença Creative Commons Attribution, que permite uso, distribuição e

cc. 
arising from the asynchrony in the flowering phenology of chosen parents, thus enabling controlled pollination programs. After establishing the basics of floral biology and breeding system, anthers of flowers were collected in three developmental stages: flower buds, at pre-anthesis and at anthesis. The anthers were desiccated and stored at $-16^{\circ} \mathrm{C}$ for up to 360 days. After this period the pollen grains were extracted and analyzed for their morphology and viability. The number of pollen grains per anther was higher in flower buds and pre-anthesis. The diameter of pollen grains gradually increased from flower buds to in anthesis. In flower buds the exine was thinner when compared to the other two stages. The percentage of viable pollen grains was high (above $88 \%$ ) in all three flower development stages, even at 360 days of storage. We concluded that storage period of $T$. ciliata pollen grains can exceed 360 days and that flower buds can be used for controlled pollinations in breeding programs.

Keywords: Australian red cedar; Pollen diameter; Crossing system; Controlled pollination.

\section{INTRODUÇÃO}

As florestas plantadas no Brasil são predominantemente equiâneas, homogêneas e constituídas por espécies exóticas dos gêneros Eucalyptus, Corymbia e Pinus. Este predomínio é resultante da capacidade de adaptação e das altas taxas de produtividade destas espécies para abastecer, principalmente, o setor de siderurgia a carvão vegetal e o de celulose e papel (Associação Brasileira de Florestas Plantadas, 2012).

Entretanto, setores econômicos como o da construção civil e da indústria moveleira têm apresentado demandas de matérias-primas que agreguem mais valor aos seus produtos finais. Assim, novas áreas de florestas estão sendo plantadas, sendo que o cedro australiano (Toona ciliata M. Roemer) tem se destacado como uma das espécies mais promissoras (Souza et al., 2010).

O destaque da referida espécie, dentre outras do grupo denominado de "novas madeiras", se deve às suas propriedades tecnológicas que conferem alto valor comercial para usos na indústria madeireira, principalmente na moveleira. Além de ser bem adaptada às condições climáticas de várias regiões brasileiras, o cedro australiano é uma espécie da família Meliaceae que é resistente aos ataques de Hypsiphyla grandella (Bygrave \& Bygrave, 2005), uma broca do ponteiro muito comum em espécies do gênero Cedrela P. Browne (cedros brasileiros) e Swietenia Jacq. (mogno brasileiro). Essa resistência possibilita que a espécie forme um fuste de alta qualidade por ser relativamente reto e monopodial (Nassur et al., 2013).

Apesar dessas vantagens mencionadas e o reconhecido valor da espécie para a silvicultura brasileira, ela ainda se encontra em estágios iniciais de melhoramento genético. $O$ seu sistema reprodutivo é por via sexual, com sistema de acasalamento por fecundação predominantemente cruzada, o que define a aplicação do método de melhoramento genético aplicável para plantas alógamas.

Seguindo os princípios desse método, instalou-se no município de Campo Belo (MG) o primeiro teste de procedências/progênie/planta de $T$. ciliate no Brasil, envolvendo 71 progênies de 16 procedências distintas da costa leste da Austrália, cujas árvores matrizes amostradas se localizam nos estados de Queensland e New South Wales.

Após 10 anos de teste, procederam-se às primeiras seleções de indivíduos geneticamente superiores para uso em pomares de sementes clonais e utilização como genitores para constituição das gerações avançadas de melhoramento genético. Como esses indivíduos são de procedências geneticamente distintas (Santos, 2011), ocorreu uma grande variação nas fenofases do florescimento, com consequente assincronia na emissão e amadurecimento dos órgãos sexuais, tornando as polinizações controladas praticamente inexequíveis.

Esses indivíduos superiores já foram resgatados, por enxertia, do referido teste genético e estão sendo transferidos para jardins de polinizações controladas. A condução destas polinizações em delineamentos de cruzamentos apropriados para se produzir novas progênies de irmãos completos e para avaliar a heterose depende, entretanto, da solução dos obstáculos decorrentes da mencionada assincronia de florescimento. Tal solução pode ser alcançada pelo armazenamento de grãos de pólen em condições e tempo que garantam as 
suas viabilidades em níveis adequados para a condução das polinizações controladas desejadas.

Assim, neste contexto, esse estudo tem o objetivo de avaliar o estádio de desenvolvimento das flores mais propício para a coleta de grãos de pólen, bem como o tempo de armazenamento que possa garantir as suas viabilidades em níveis que garantam o sucesso das necessárias polinizações controladas.

\section{MATERIAL E MÉTODOS}

Inflorescências de cedro australiano foram coletadas em 22 indivíduos no município de Campo Belo - MG, cultivados a partir de uma mistura de sementes excedentes da instalação de um teste de procedência/progênie/plantas instalado no ano de 2016. As coordenadas geográficas do referido município são 2053'58,89"S, 45¹7'33,04"W, com altitude média é de $945 \mathrm{~m}$ e precipitação pluviométrica média anual é de $1.250 \mathrm{~mm}$, com chuvas bem distribuídas e temperatura média anual de $23,5^{\circ} \mathrm{C}$

\section{Morfologia floral e do grão de pólen}

A espécie floresce entre os meses de setembro a novembro e os frutos aparecem de janeiro a março, no entanto, estes eventos podem ser antecipados em mais de um mês (Souza et al., 2010). A abertura das flores ocorre entre 07:00 e 13:00 h e o momento da antese é afetado pelo aumento ou diminuição na temperatura (Singh \& Gupta, 2017).

Conforme descrito por Kodela (2006), o grão de pólen de T. ciliata é 3-4 colporato, isopolar, radiosimétrico, pequeno, circular ou ligeiramente oval, raramente oblato. A camada de exina possui cerca de 1,0 $\mu \mathrm{m}$ de espessura, mas nos colpos a espessura é de 1,8-2,0 $\mu \mathrm{m}$. 0 eixo polar médio possui $21,0 \mu \mathrm{m}$ e o eixo equatorial, $20,0 \mu \mathrm{m}$.

Os materias genéticos já selecionados para dar continuidade ao programa de melhoramento da $T$. ciliata apresentam inflorescências com arquitetura típica da espécie (Figura 1), onde as ramificações secundarias do eixo principal contêm cimeiras em quantidades váriáveis, tal como descrito por Gouvêa et al. (2008).

A Figura 1 apresenta uma dessas ramificações e suas cimeiras com frutos já formados ou com as flores funcionais femininas em pós-antese (provavelmente já fecundadas) e as flores funcionais masculinas se encontram fechadas ou em pré-antese. Nota-se que o arranjo dessas flores não é aleatório, as femininas se localizam centralmente e as masculinas paralelamente.

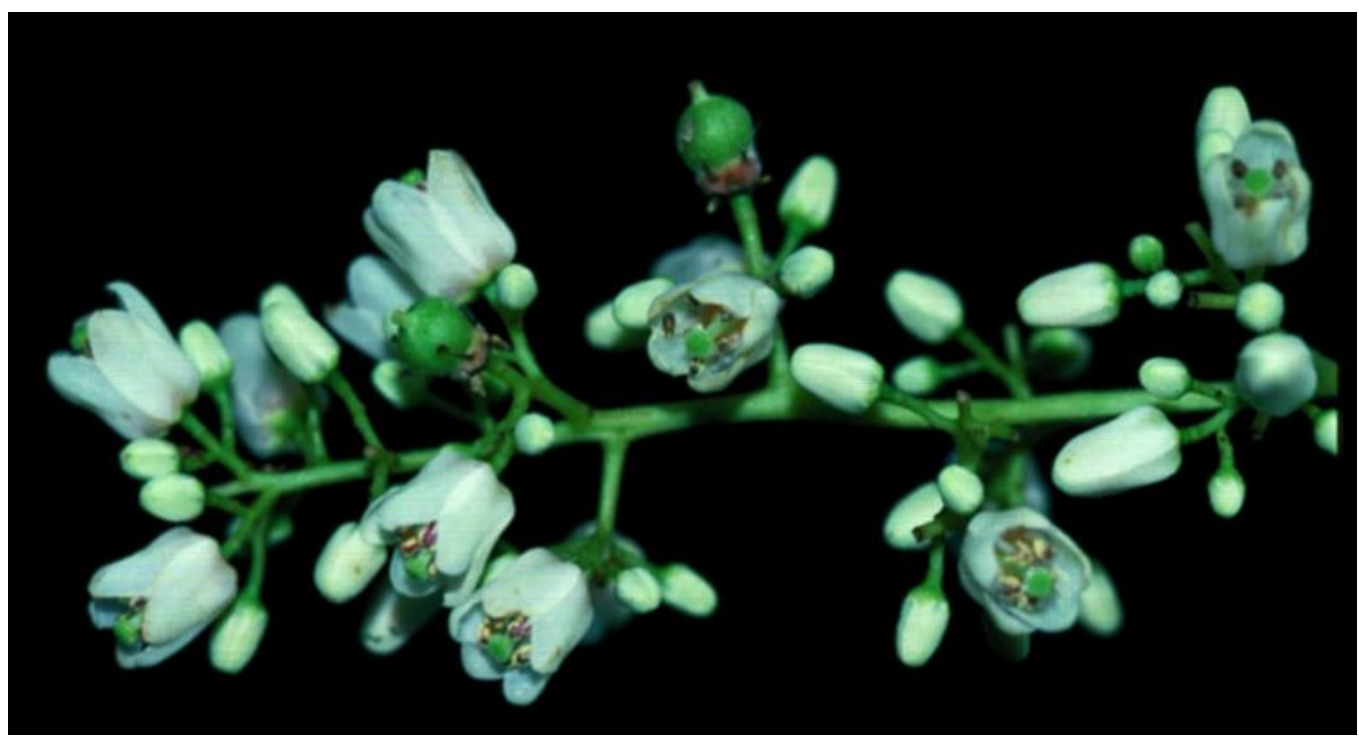

Figura 1. Arranjo não aleatório de flores de um ramo secundário do eixo principal de uma inflorescência de Toona ciliata. 
Esses dois tipos diferentes de flores, apresentadas na Figura 2 em secções longitudinais, exibem a presença de estames rudimentares e não funcionais nas flores maiores, centrais e em pós-antese (flor feminina) e de pistilos rudimentares e não funcionais nas flores menores laterais em pré-antese (flor masculina). Segundo Gouvêa et al. (2008), tais características se constituem na principal evidência de que a flor de T. ciliata é morfologicamente bissexual, mas funcionalmente unissexual, e que a distribuição sexual dentro das inflorescências não é aleatória.

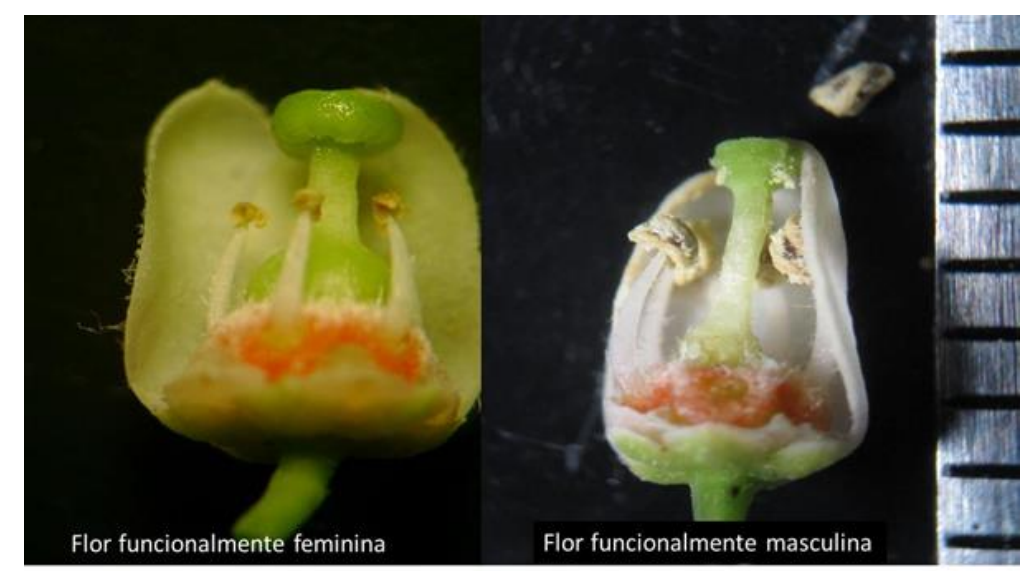

Figura 2. Secções longitudinais de flores de Toona ciliata mostrando estames rudimentares e pistilo normalmente desenvolvido na flor funcionalmente feminina (esquerda) e pistilo rudimentar e estames normalmente desenvolvidos na flor funcionalmente masculina (direita). Os nectários aparecem em ambas as flores na cor laranja. Escala apresentada em milímetros.

\section{Obtenção e avaliação dos grãos de pólen}

Separaram-se anteras de flores funcionalmente masculinas em três estádios durante a antese: botão floral, flor em pré-antese e flor em antese. Estas anteras foram colocadas em placas de Petri separadas, permaneceram 48 horas em dessecador com sílica gel e posteriormente foram armazenadas em tubos de plástico de $1,5 \mathrm{ml}$ a uma temperatura de $-16^{\circ} \mathrm{C}$, por 360 dias.

Flores nos três estádios durante a antese foram emblocadas com objetivo de fotomicrografar as anteras. A medição do diâmetro dos grãos de pólen $(\mu \mathrm{m})$ e o número de grãos de pólen por teca foram medidos diretamente por meio do uso do software UTHSCSA-Imagetool.O delineamento experimental utilizado foi o inteiramente casualizado, composto por 3 tratamentos (estádios da flor durante a antese) e 13 repetições, totalizando um número amostral de 39.

Para aferição da espessura da exina, anteras nos três estádios da flor foram preparadas, fotografadas em Microscópio Eletrônico de Transmissão modelo LEO 906 Zeiss e avaliadas no software UTHSCSA-Imagetool. O delineamento experimental utilizado foi o inteiramente casualizado, composto por 3 tratamentos (estádios da flor durante a antese), 40 repetições, totalizando um número amostral de 120.

A viabilidade dos grãos de pólen armazenados foi testada por meio de coloração com carmim acético 1\%, em dois tempos de armazenamento (120 e 360 dias). Utilizaram-se fotomicrografias para quantificar o número de grãos de pólen viáveis (corados de vermelho) e não viáveis (não corados), nos diferentes estádios da flor durante a antese, por meio do uso do software de análise de imagem UTHSCSA-Imagetool. O delineamento experimental utilizado foi o inteiramente casualizado, composto por 3 tratamentos (estádios da flor durante a antese), 7 repetições, com 4 campos por repetição, totalizando um número amostral de 84 .

Para todas as variáveis medidas, os dados foram submetidos à análise de variância e as médias comparadas pelo teste de Scott-Knott $(p<0,01)$.

\section{RESULTADOS E DISCUSSÃO}

As observações microscópicas para avaliar a formação, viabilidade e ploidia dos grãos de pólen em cada dos estádios florais são apresentadas na Figura 3. A imagem 3A evidencia grãos 
de pólen corados com a solução de Alexander, onde a coloração roxa e azul indicam, respectivamente, os pólens viáveis e os abortados e, portanto, inviáveis. Nessa imagem, notase uma alta proporção de pólens viáveis em relação aos inviáveis, sendo que aqueles com maior diâmetro (seta tracejada) apresentam ploidia 2n, em contraste com os de menor dimensão (seta cheia) que apresentam ploidia $\mathrm{n}$.

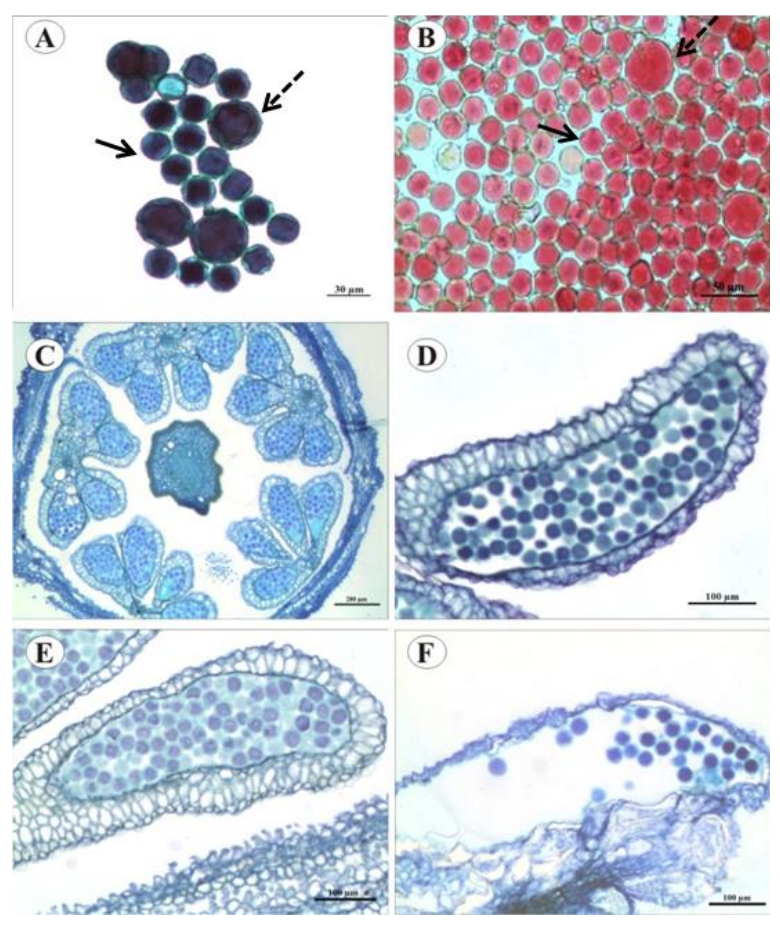

Figura 3. Anteras e grãos de pólen de Toona ciliata. (A) Grãos de pólen com ploidia n (seta cheia) e $2 \mathrm{n}$ (seta tracejada), corados com solução Alexander. (B) Grãos de pólen n (seta cheia) e 2n (seta tracejada) corados com carmim acético 1\%. (C) Cinco anteras com duas tecas cada, em flor fechada. (D) Detalhe de uma teca da antera de botão floral em secção longitudinal. (E) Detalhe de antera de flor em pré-antese, em secção longitudinal. (F) Detalhe de antera de flor em antese em secção longitudinal, onde parte do pólen já foi disperso naturalmente.

Do mesmo modo, a Figura 3B, onde o corante utilizado foi o carmim acético 1\%, faz a distinção dos esporos viáveis (com coloração mais avermelhada) dos não viáveis. As setas cheias e tracejadas apontam para os pólens com ploidia $n$ e $2 n$, respectivamente. Os resultados de ploidia indicam que o diâmetro do grão de pólen pode ser utilizado para diferenciar acessos haploides e diploides.

Os grãos de pólen de tamanho maior provavelmente são pólens não reduzidos, isto é, pólen 2n (Figuras 3A e 3B). O diâmetro médio desses pólens é de 38,15 $\mu \mathrm{m}$, ou seja, 1,6 vezes maior que o do pólen reduzido. Xue et al. (2011) consideraram, para Ziziphus jujuba, que o diâmetro do pólen $2 \mathrm{n}$ é aproximadamente 1,5 vezes maior que o do pólen haploide $\mathrm{n}$. Isso pode ser explicado devido a maior quantidade de DNA contida em pólen 2 n, aumentando o seu diâmetro (Dewitte et al., 2009).

Apesar dos grãos de pólen $2 \mathrm{n}$ aparecerem em baixa frequência $(0,68 \%)$ e com baixa viabilidade $(33,64 \%)$ no caso de $T$. ciliata, espera-se que com o avanço dos programas de melhoramento genético desta espécie, grãos de pólen $2 n$ poderão ser utilizados para a obtenção de poliploides.

A existência de grãos de pólen completamente formados em um estádio de desenvolvimento de botão floral (como evidenciado na Figura 3C que mostra cinco anteras com duas tecas cada) sugere que essas anteras podem ser colhidas antes da abertura das flores para a extração de pólen. Esta prática pode reduzir a contaminação por pólens 
estranhos e indesejados, dada a grande visitação de polinizadores em flores em antese devido à presença de nectários nas flores de ambos os sexos. Por exemplo, em Swietenia macrophylla a produção de pólen é muito reduzida, o que reforça a necessidade de uma recompensa adicional, como o néctar, para atrair visitantes florais (Paiva, 2012; Singh \& Gupta, 2017).

As Figuras 3D, 3E e 3F apresentam secções longitudinais das tecas de anteras colhidas em botão floral, em pré-antese e em antese, respectivamente. Nessas três imagens observase grande quantidade de pólen em tecas de botões florais e em pré-antese, enquanto que nas flores em antese o estoque de pólen foi bastante reduzido, sugerindo que nesse estádio de desenvolvimento das flores os grãos de pólen já poderiam ter sido dispersos naturalmente, sendo, portanto, uma fase desaconselhável para a coleta de pólen.

Contudo, a coleta das anteras não deve se basear exclusivamente na presença de pólen encontrada dos diferentes estádios de desenvolvimento da flor. É necessário o conhecimento da quantidade e viabilidade dos grãos de pólen, em cada um dos três estádios de desenvolvimento floral, ao longo de um período de tempo necessário para armazenamento em médio ou longo prazo, considerando, consequentemente, o tempo demandado para a superação dos obstáculos impostos pela assincronia na fenologia da floração.

A Tabela 1 mostra que a maior quantidade de pólen foi estimada para as flores em préantese e botões florais, que apresentaram, respectivamente, 3.276 e 2.692 grãos de pólen. A semelhança estatística verificada se deu pelo alto desvio padrão (1570) registrado nas estimativas em flores em pré-antese.

Tabela 1. Número de grãos de pólen de Toona ciliata e percentual médio de viabilidade do pólen em dois tempos de armazenamento (120 e 360 dias) avaliada por meio de carmim acético 1\%, em função do estádio da flor durante a antese.

\begin{tabular}{|c|c|c|c|}
\hline $\begin{array}{c}\text { Estádio de } \\
\text { desenvolvimento da flor }\end{array}$ & $\begin{array}{l}\text { Número médio }( \pm \mathrm{dp}) \text { de } \\
\text { grãos de pólen }\end{array}$ & $\begin{array}{c}\text { Viabilidade }(\% \pm d p) \text { após } \\
120 \text { dias }\end{array}$ & $\begin{array}{c}\text { Viabilidade }(\% \pm \mathrm{dp}) \text { após } \\
360 \text { dias }\end{array}$ \\
\hline Botão floral & $2692 \pm 404(a)$ & $96,5 \pm 2,4$ (Aa) & $88,7 \pm 17,4(\mathrm{Ba})$ \\
\hline Flor em pré-antese & $3276 \pm 1570$ (a) & $95,2 \pm 2,8(\mathrm{Aa})$ & $93,1 \pm 6,1(\mathrm{Ba})$ \\
\hline Flor em antese & $1418 \pm 442(b)$ & $97,6 \pm 2,4(\mathrm{Aa})$ & $91,1 \pm 9,9(\mathrm{Ba})$ \\
\hline
\end{tabular}

As médias seguidas pela mesma letra minúscula não diferem entre si pelo teste de Scott-Knott $\mathrm{P}<0,05$ (colunas). As médias seguidas pela mesma letra maiúscula não diferem entre si pelo teste de $\operatorname{Scott-Knott~}(p<0,01)$ (linhas). dp= desvio padrão.

A Tabela 1 também mostra que os percentuais de viabilidade dos grãos de pólen, após 120 dias de armazenamento, foram superiores a 95,2\% em todos os três estádios de desenvolvimento da flor, e que as diferenças entre os três estádios não foram significativas. O mesmo se verificou para o tempo de 360 dias de armazenamento, no qual os percentuais médios de viabilidade foram superiores a $88,7 \%$. Diferenças significativas somente foram observadas entre os tempos de armazenamento de 120 e 360 dias, independentemente do estádio de desenvolvimento da flor. A maior queda $(7,8 \%)$ foi observada no estádio de botão floral e a menor $(2,1 \%)$ foi para o estádio de pré-antese. Apesar dessas mencionadas quedas, a viabilidade dos grãos de pólen permaneceu alta independentemente do nível de maturação das flores, o que indica que anteras podem ser coletadas em qualquer um dos estádios estudados.

A manutenção desses altos níveis de viabilidade por 360 dias de armazenamento indica que ela poderá ser estendida por um tempo bem mais longo, para que os obstáculos da assimetria na fenologia da floração sejam superados e a realização de cruzamentos preferenciais possam ser conduzidos para um maior número de genitores e, assim, produzir maior quantidade de progênies de irmãos completos para ampliar a base genética necessária à condução das gerações avançadas de seleção.

O trabalho de Pereira et al. (2002), conduzido em clones de Eucalyptus camaldulensis e E. urophylla registrou uma viabilidade de pólen de $40 \%$ após três meses de armazenamento. Estes autores consideraram este valor como uma percentagem alta devido à quantidade de pólen que se empregada nas polinizações. Desta forma, os valores de viabilidade de pólen encontrados no presente trabalho podem ser 
considerados muito elevados e capazes de garantir o sucesso de hibridações intraespecíficas (entre as diferentes procedências de T. ciliata).

A Tabela 2 mostra o aumento significativo na espessura da exina de acordo com o estádio de desenvolvimento da flor. A espessura da exina do pólen foi menor em botões florais do que nas flores em pré-antese e em antese, sendo que a diferença de espessura nesses dois últimos estádios não foi significativa. De acordo com Furness (2007), uma exina de menor espessura pode oferecer menor resistência à germinação do pólen e crescimento do tubo polínico. Portanto, a utilização do pólen coletado em botões florais pode representar uma vantagem durante a polinização de T. ciliata.

A Tabela 2 também mostra diferenças significativas no diâmetro dos grãos de pólen. O menor diâmetro $(22,5 \mu \mathrm{m})$ foi observado em botões florais e o maior $(23,5 \mu \mathrm{m})$ nas flores em antese. $\mathrm{O}$ aumento da espessura da exina pode explicar o acréscimo em diâmetro dos grãos de pólen do estádio de botão floral para o de pré-antese. Pacini (1990) sugere que o volume do pólen aumenta durante a formação das camadas de exina e intina. Já o aumento em diâmetro do pólen observado do estádio de pré-antese para o de antese pode ser explicado pela expansão do pólen devido à presença de vacúolos, como relatado por Pacini et al. (2011). Esses autores também ressaltam que a exina desempenha um papel fundamental na acomodação do volume do pólen durante a absorção e perda de água.

Tabela 2. Diâmetros médios e espessura média da exina dos grãos de pólen de Toona ciliata em função do estádio de desenvolvimento da flor durante a antese.

\begin{tabular}{ccc}
\hline $\begin{array}{c}\text { Estádio de } \\
\text { desenvolvimento da flor }\end{array}$ & $\begin{array}{c}\text { Espessura Média da exina } \pm \mathbf{d p} \\
(\boldsymbol{\mu m})\end{array}$ & $\begin{array}{c}\text { Diâmetro médio do pólen } \pm \mathbf{d p} \\
(\boldsymbol{\mu m})\end{array}$ \\
\hline Botão floral & $0,94 \pm 0,08 \mathrm{~b}$ & $22,5 \pm 0,9(\mathrm{c})$ \\
Flor em pré-antese & $1,06 \pm 0,11 \mathrm{a}$ & $23,1 \pm 1,0(\mathrm{~b})$ \\
Flor em antese & $1,08 \pm 0,16 \mathrm{a}$ & $23,5 \pm 1,4(\mathrm{a})$
\end{tabular}

As médias seguidas pela mesma letra na coluna não diferem entre si pelo teste de Scott-Knott $(p<0,01)$. dp= desvio padrão.

A Figura 4 mostra que os grãos de pólen estão completamente desenvolvidos nos botões florais, com dois núcleos claramente distintos. O núcleo vegetativo da espécie apresentou formato fusiforme $(P / E=2,09)$, enquanto o reprodutivo foi esférico $(P / E=0,92)$ (Figura 4). Esta diferença morfológica é importante em função da necessidade de identificar estes dois núcleos em estudos posteriores, relacionados com o desenvolvimento dos grãos de pólen, estádios de maturação e mesmo formação do tubo polínico. Percebe-se que, mesmo no estádio de dispersão (antese) os grãos de pólen de $T$. ciliata não possuem dois núcleos reprodutivos, sendo que este segundo provavelmente se desenvolverá durante o crescimento do tubo polínico.

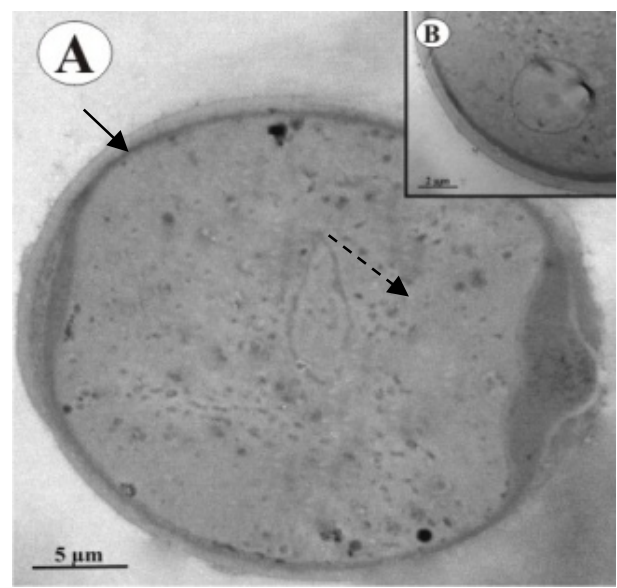

Figura 4. Eletromicrografia do grão de pólen de botão floral de Toona ciliata. (A) camada mais clara de exina (seta cheia) e núcleo vegetativo fusiforme (seta tracejada). (B) núcleo reprodutivo esférico (seta cheia). 


\section{CONCLUSÃO}

A integridade dos grãos de pólen registrados pela eletromicrografia em botão floral, e a grande quantidade de grãos pólen viáveis no interior das tecas dessas anteras, mesmo após 360 dias de armazenamento, indicam que polinizações controladas em T. ciliata podem ser realizados com pólen originado de botões florais. Devido à provável ausência ou à reduzida frequência de visita de polinizadores nessas flores, espera-se, nessa situação, uma maior pureza nos estoques de grãos de pólen e, consequentemente, maiores garantias de pedigree das progênies a serem constituídas por polinização controlada.

\section{REFERÊNCIAS}

Associação Brasileira de Florestas Plantadas - ABRAF. (2012). Anuário estatístico da ABRAF 2012, ano base 2011 (150 p.). Brasília: ABRAF.

Bygrave, F., \& Bygrave, P. (2005). Growing australian red cedar and other Meliaceae species in plantation (60 p.). Barton: Rirdc. Recuperado em 13 de setembro de 2011, de http://findarticles.com/p/articles/mi_7252/is_2_69/ai_n31677 196/

Dewitte, A., Eeckhaut, T., Van Huylenbroeck, J., \& Van Bockstaele, E. (2009). Occurrence of viable unreduced pollen in Begonia collection. Euphytica, 168(1), 81-94. http://dx.doi.org/10.1007/s10681009-9891-X.

Furness, C. A. (2007). Why does some pollen lack apertures? A review ofinaperturate pollen in eudicots. Botanical Journal of the Linnean Society, 155(1), 29-48. http://dx.doi.org/10.1111/j.10958339.2007.00694.x.

Gouvêa, C. F., Dornelas, M. C., \& Rodriguez, A. P. (2008). Floral development in the Tribe Cedreleae (Meliaceae, Sub-family Swietenioideaea): Cedrela and Toona. Annals of Botany, 101(1), 39-48. PMid:17981877. http://dx.doi.org/10.1093/aob/mcm279.

Kodela, P. G. (2006). Pollen morphology of some rainforest taxa occurring in the lllawarra region of New South Wales, Australia. Telopea, 11(3), 346-389. http://dx.doi.org/10.7751/telopea20065734.

Nassur, O. A. C., Rosado, L. R., Rosado, S. C. S., \& Carvalho, P. M. (2013). Variações na qualidade de toras de Toonaciliata M. Roem. com dezoito anos de idade. Cerne, 19(1), 43-49. http://dx.doi.org/10.1590/S0104-77602013000100006.

Pacini, E. (1990). Harmomegathic characters of Pteridophyta spores and Spermatophyta pollen. Plant Systematics and Evolution, 5, 53-69.

Pacini, E., Jacquard, C., \& Clement, C. (2011). Pollen vacuoles and their significance. Planta, 234(2), 217227. PMid:21706335. http://dx.doi.org/10.1007/s00425-011-1462-4.

Paiva, E. A. S. (2012). Anatomy, ultrastructure, and secretory of the floral nectaries in Swietenia macrophylla (Meliaceae). American Journal of Botany, 99(12), 1910-1917. PMid:23174914. http://dx.doi.org/10.3732/ajb.1200122.

Pereira, R. C., Davide, L. C., Ramalho, M. A. P., \& Andrade, H. B. (2002). Alternativas para aumentar a eficiência dos cruzamentos em programas de melhoramento de Eucalyptus. Cerne, 8(2), 60-69.

Santos, A. M. (2011). Melhoramento genético do cedro australiano (Toonaciliata M. Roemer var. australis) (Tese de doutorado). Universidade Federal de Lavras, Lavras.

Singh, T. J., \& Gupta, T. (2017). Studies of the Reproductive Biology of Toonaciliata M. Roem under the Himachal Pradesh Condition. International Journal of Bio-Resource and Stress Management, 8(3), 437 443. http://dx.doi.org/10.23910/IJBSM/2017.8.3.1737.

Souza, J. C. A. V., Barroso, D. G., \& Carneiro, J. G. A. (2010). Cedro australiano (Toonaciliata) (Vol. 21, Manual Técnico, 12 p.) Niterói: Programa Rio Rural.

Xue, Z., Liu, P., \& Liu, M. (2011). Cytological mechanism of 2n pollen formation in Chinese jujube (Ziziphus jujuba Mill. 'Linglingzao'). Euphytica, 182(2), 231-238. http://dx.doi.org/10.1007/s10681-0110461-7.

Contribuição dos Autores: CTV: conceituação, curadoria de dados, análise formal, investigação, metodologia, escrita - primeira redação, escrita - revisão e edição; SCSR: conceituação, curadoria de dados, análise formal, investigação, metodologia, supervisão, recursos, escrita - revisão e edição; FJP: conceituação, curadoria de dados, análise formal, investigação, metodologia, supervisão, recursos, escrita - revisão e edição. 